ARTICULO DE INVESTIGACION

\title{
ALIANZA ESCUELA - FAMILIA: UN APORTE AL CAPITAL SOCIAL.
}

\section{ALLIANCE SCHOOL-FAMILY A CONTRIBUTION TO THE SOCIAL CAPITAL}

Maria del Carmen Vergara Quintero ${ }^{1}$

\begin{abstract}
Palabras Clave: Familia, escuela, capital social, niñez ,cultura, sociedad
Key words: Family, school, social capital, childhood, culture, society.
\end{abstract}

\section{ABSTRACT.}

The family and the school are a referential frame essential for the incorporation of a new human being to the society, however, this frame is found to be exposed to the changes imposed by the diverse transformations that are to be assumed by both institutions in order to respond to their educative and socializing task.

The following revision on the alliance family-school aims at supporting the potential that would be obtained through the strengthening of such

1 Odontóloga. Magíster en Administración en salud, Doctora en Ciencias Sociales Niñez y Juventud. Docente e investigadora de la Universidad Autónoma de Manizales y del Observatorio de juventud de Caldas, Miembro del Grupo en Investigación en Desarrollo Regional de la UAM.

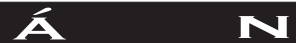

Universidad Autónoma de Manizales

\section{$\mathbf{R}$}

Año I4, Número 23, julio - diciembre 2007 
relation, particularly on the regions that look for a development that promotes the human capacities, of the individual, the institutions and the context in general.

Based on the information above the social capital, the school and the family are defined inside the cultural-historical line as well as they are considered from an international and national perspective according to several research that have been carried out on the alliance family-school.

\section{RESUMEN.}

La Familia y la Escuela son un marco referencial imprescindible para la incorporación de un nuevo ser humano a la sociedad, pero este marco se encuentra a merced de los avatares impuestos por transformaciones diversas que han de asumir ambas instituciones para responder a su tarea educativa y socializadora.

La siguiente revisión sobre la alianza familia y escuela busca fundamentar el potencial que tiene fortalecer dicha relación, específicamente en las regiones que buscan un desarrollo que potencie las capacidades humanas tanto del individuo, las instituciones y del contexto en general.

Es por lo anterior que se define el capital social, la escuela y la familia dentro de la línea histórico cultural y se define bajo la lectura de varias investigaciones que han estudiado la alianza familia y escuela, desde el referente nacional e internacional.

\section{INTRODUCCIÓN}

Familia y Escuela son un marco referencial imprescindible para la incorporación de un nuevo ser humano a la sociedad, pero este marco se encuentra a merced de los avatares impuestos por transformaciones diversas que han de asumir ambas instituciones para responder a su tarea educativa y socializadora.

Los cambios de la sociedad actual son rápidos y profundos, los sujetos no están preparados para adaptarse a ellos en los diversos niveles: 
biológico, psicológico y social. La complejidad que caracteriza la sociedad, demanda una nueva visión educadora de la familia y la escuela, lo que exige su compromiso para trabajar unidas en un proyecto común.

En el presente documento pretendo crear un espacio de reflexión sobre la necesidad de tomar conciencia del potencial de la alianza entre la escuela y la familia, como generadora de capital social para lograr que: -Los profesionales de la educación o profesores y los padres o acudientes de los niños mejoren las relaciones, como una medida para lograr calidad en la enseñanza y prevención del fracaso escolar.

- La familia tome conciencia de su papel en la educación de sus hijos para responder a las nuevas necesidades educativas que ellos presentan.

- La escuela trabaje en red con la familia de tal modo que se fortalezcan sus relaciones como aporte al capital social.

La familia y la escuela han ido cambiando sus sensibilidades y ritualidades debido a un acelerado proceso de cambio cultural y social, como es la creciente presencia de los medios de comunicación de masas, la explosiva importancia del consumo y la veloz emergencia de las nuevas tecnologías, hasta el punto que han delegado funciones que en otras épocas eran de cabal importancia en el proceso de socialización de los individuos.

Pero ¿cuáles son las posibilidades de cambio que nos aventura la nueva sociedad del conocimiento y que en la actualidad algunos autores como Muñoz, G. (2005) Ilaman sociedad RED?. ¿Cómo puede apoyar la alianza entre la familia y escuela a la consolidación de capital social?

Las características de la educación Colombiana de nuestros días y las políticas educativas derivadas de ellas, apuntan a la necesidad de una comunicación e interacción familia-escuela más estrecha que la que se visualizaba en décadas anteriores. Esas interrelaciones, tanto en su naturaleza como en su dinámica ponen en evidencia una relación compleja en el marco de una sociedad cambiante y pluricultural.

Cabe destacar que la interacción entre la familia y la escuela no se sustenta en la suma de propiedades individuales como roles, valores,

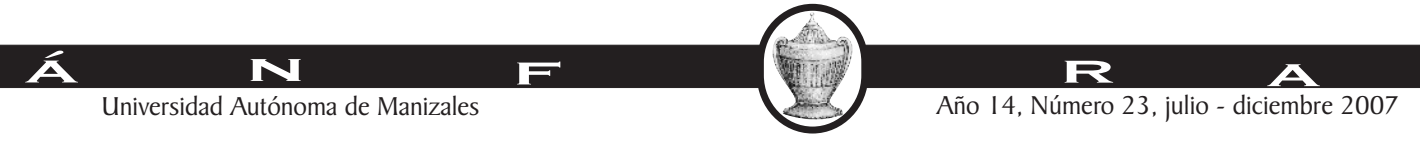


motivaciones o expectativas de sus miembros, por el contrario se constituye en un todo inseparable, es así como cualquier cambio en uno de ellos provoca cambios en todos los demás. Es más, al comportarse como totalidad inseparable, las secuencias comunicativas recíprocas de sus participantes conformarían un patrón emergente. Además, tanto al interior de la familia como también al interior de la escuela, el comportamiento de cada actor está relacionado con el de los demás miembros y depende a la vez de ellos, lo que explica que muchas veces emerjan problemas interactivos que trascienden las características individuales de sus miembros.

Las transformaciones de la última década han tornado difusos aquellos valores y símbolos colectivos tradicionales a partir de los cuales la gente orientaba su vida en la sociedad. Hoy en día la imagen de sociedad y la identidad de quienes habitan en ella no son evidentes, como tampoco los valores y las orientaciones que darán sustento a las nuevas formas de vida social que están emergiendo con los cambios.

Dowling, E $(1996,1)$ señala cómo los problemas de los niños deben ser orientados en forma sistémica entre la familia y la escuela. Manifiesta como las familias en los últimos años han experimentado cambios crecientes en sus modelos y estilos de vida en ese medio cambiante y cómo la relación entre la familia y la escuela sigue evolucionando de modo que los niños y los jóvenes actúan como pivotes entre ambos sistemas. Muestra además, cómo la familia y la escuela son los dos sistemas más influyentes en el desarrollo del individuo, sin embargo estos dos sistemas abiertos no están en constante interacción. Es por lo anterior que se hace necesario mostrar cómo la construcción de alianzas efectivas entre ambas instituciones aportaría al capital social de puente en la medida que se produce un nuevo conocimiento por la unión de dos instituciones que siempre han caminado aisladas aunque comparten un gran número de funciones y responsabilidades en la tarea de formar los niños, niñas y jóvenes.

A continuación definiré tres categorías esenciales que permitirán la comprensión de la alianza familia y escuela como son: capital social, familia y escuela con el fin de describir la relación o no que se ha dado en el transcurrir del tiempo.

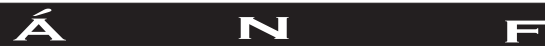

Universidad Autónoma de Manizales 


\section{CAPITAL SOCIAL.}

En la década de los '80, surgen las primeras formulaciones teóricas sobre el concepto de capital social. Consecutivamente, es en la década de los ' 90 donde se inician las revisiones críticas y reformulaciones del mismo. Hoy, pese a que se advierte un gran avance en los enfoques conceptuales respecto de la noción de capital social, hay acuerdo generalizado entre los especialistas en sostener que aún es un concepto inacabado y se encuentra en debate teórico, aunque se ha logrado establecer consenso respecto de algunos aspectos de interés ligados al concepto.

Se ha coincidido en definir que el concepto de capital social se refiere a cierto recurso intangible, que posibilita o capacita a las personas en la obtención de determinados beneficios.

John Durston, 2001 (citado por Ministerio de Planificación de ChileMIDEPLAN, 2002) en sus escritos sobre capital social, sintetiza diferentes definiciones formuladas por destacados autores, así:

Para Bourdieu (sociólogo,1985) capital social es "el agregado de los recursos reales o potenciales, ligados a la posesión de una red durable de relaciones más o menos institucionalizadas de reconocimiento mutuo".

Para Coleman (sociólogo, 1990) capital social son "los recursos socioestructurales que constituyen un activo de capital para el individuo y facilitan ciertas acciones de individuos que están dentro de esa estructura", igualmente señala que el capital social es productivo, posibilitando el logro de ciertos fines que no serían alcanzables en su ausencia.

Para Putnam (cientista político, 1993) capital social son los "aspectos de las organizaciones sociales, tales como las redes, las normas y la confianza, que facilitan la acción y la cooperación para beneficio mutuo".

A partir de estas definiciones, Durston establece que el capital social es "el contenido de ciertas relaciones sociales: las que combinan actitudes de confianza con conductas de reciprocidad y cooperación, que proporcionan mayores beneficios para aquellos que lo poseen, que lo que podría lograrse sin este activo".

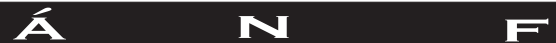

Universidad Autónoma de Manizales 
Definiendo por confianza, una actitud basada en la expectativa del comportamiento de la otra persona que participa en una relación, la confianza tiene un soporte cultural en el principio de reciprocidad, un soporte emocional en el afecto que se siente hacia personas que se muestran confiables y quienes muestran confianza en los otros; reciprocidad, se entiende como el principio rector de una lógica de interacción ajena a la lógica del mercado, que involucra intercambios basados en compensaciones de diverso tipo y por cooperación, la acción complementaria orientada al logro de objetivos compartidos de un emprendimiento en común entre las personas, grupos o comunidades.

Los autores Flores y Rello (2001) citados por MIDEPLAN (2002), sostienen que si bien existen diversas definiciones de capital social, pueden distinguirse tres componentes básicos mencionados en la mayoría de las definiciones:

1. Las fuentes y la infraestructura del capital social, es decir, lo que hace posible su nacimiento y consolidación: las normas, las redes, la cultura y las instituciones.

2. Las acciones individuales y colectivas que esta infraestructura hace posible y,

3. Las consecuencias y resultados de estas acciones, que pueden ser positivas o negativas.

Los autores complementan el análisis incorporando diferentes definiciones de capital social seleccionadas de acuerdo a esos componentes $\mathrm{y}$, coincidiendo con Durston agregan, además, a los siguientes autores:

Para Woolcock (1998) normas y redes, que facilitan la acción colectiva y el beneficio común.

Para Fukuyama (1995) recursos morales, confianza y mecanismos culturales, que refuerzan los grupos sociales.

El Banco Mundial (1998) los define como instituciones, relaciones, actitudes y valores, que gobiernan la interacción de personas y facilitan el desarrollo económico y la democracia. 
De este modo, los autores concluyen que "lo importante del capital social para los individuos y los grupos que lo poseen, es la potencialidad que les confiere y de la que carece el individuo aislado. Es decir, lo esencial del capital social es que es una capacidad. Representa pues la capacidad de obtener beneficios a partir del aprovechamiento de redes sociales".

Otras variaciones en la definición del concepto, establecen distinciones sobre la noción de capacidad, y es así como algunas sostienen que esta capacidad radica principalmente en las características individuales de los sujetos. Mientras que otras, enfatizan que esta capacidad tiene su origen en el ámbito de la cultura. Y, por último, se postula que la capacidad, posee su origen en los sistemas sociales complejos y en los múltiples agentes que lo componen.

En el mismo sentido, se ha sostenido que el capital social también puede ser visto como el atributo de individuos expresado en las redes a las cuales tienen acceso y/o en el atributo de las estructuras sociales que son propiedad de comunidades, clases y sociedades enteras.

En esta misma línea, se plantea que en el concepto de capital social es posible distinguir los siguientes elementos:

- memoria Social

- Identidad (incluida Etnicidad)

- Religión

- Vecindad

- Amistad

- Parentesco

- Principios de Reciprocidad horizontal y vertical

- Satisfactores socio-emocionales: pertenencia, afecto, honra, prestigio, autoestima, altruismo, entre otros.

Todos estos elementos son universales y existen en potencia en todos los grupos humanos, lo que varía es la magnitud y la forma en que se combinan de un grupo a otro, la presencia de cualquiera de los elementos no determina automáticamente la presencia de capital social, algunos actúan independientemente y otros, en forma compleja y combinada, algunos son utilizables por individuos, en cambio otros por colectividades o por ambos. 
De acuerdo con Durston, las diversas concepciones teóricas ponen en relieve que el concepto es aplicable, utilizable $y$, su importancia radica en que cambia el análisis reduccionista que se ha hecho hasta el momento y afirma que el capital social no es un concepto neutral sino más bien progresista y revolucionario.

Es posible evidenciar un intenso debate de gran interés con relación al tema del capital social, rico en distinciones y altamente relevante para orientar el diseño de políticas públicas destinadas a la promoción de la participación de la familia en la escuela, que permita asumir una alianza donde se privilegien las "relaciones sociales" por sobre los discursos normativos, es decir, que se haga énfasis en el contexto social y no individual, de manera que, el capital social se inserte en el plano conductual de las relaciones y de los sistemas sociales.

\section{Tipos de capital social.}

Siguiendo a Durston citado por MIDEPLAN (2002) ${ }^{2}$, el capital social puede manifestarse de diferentes formas, pudiéndose distinguir al menos cinco formas de presentación: individual, grupal, comunitario o de barrio, de puente y societal.

1. Capital social individual: Se manifiesta en relaciones sociales con características de un contrato diádico con contenido de confianza y reciprocidad, y se extiende a través a redes egocentradas. El capital individual es el recurso que las personas han acumulado en sus relaciones sociales, previstas de favores que han realizado y que en cierto momento reclaman su reciprocidad.

Este recurso no reside en la persona misma a nivel individual sino en las relaciones entre personas. En otras palabras, el capital social individual se caracteriza por cierta reciprocidad difusa, un contrato informal entre dos personas, y se expresa en redes centradas en cada persona.

2. Capital social grupal: Es una extensión de las redes individuales egocéntricas que se cruzan una a una en un grupo, las relaciones se cruzan entre sí y se densifican conformando un grupo capaz de funcionar como equipo. En el grupo pueden conformarse relaciones de poder en forma horizontal o vertical, por lo general se da en grupos donde existe un líder que convoca y mueve el grupo. El capital social
2 Síntesis de los principales enfoques, métodos y estrategias para la superación de la pobreza. Documento de Trabajo elaborado por u $\mathrm{n}$ e q u i po d e profesionales del Departamento de Evaluación Social, de la División Social del Ministerio d e PIanificación y Co o p e r a c i ó n (MIDEPLAN) del Gobierno de Chile. Esto, en el marco del Seminario "Perspectivas Innovativas en Política Social. Experiencias relevantes para la superación de la pobreza: Una mirada desde lo posible", realizado durante los días 29 y 30 de Octubre $\mathrm{d}$ e I 2002 . www.mideplan.cl

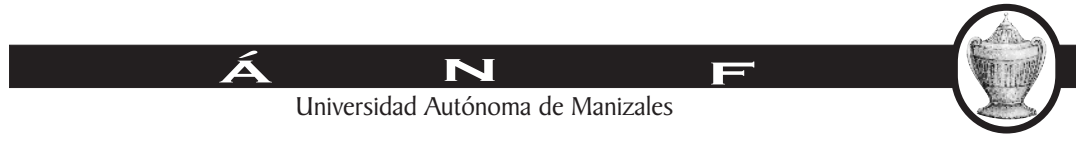


grupal opera sobre la base de la reciprocidad individual entre los miembros del grupo.

3. Capital social comunitario y de barrio: Consta de las estructuras que conforman las instituciones de cooperación grupal. Reside no sólo en el conjunto de las relaciones interpersonales diádicas sino en sistemas complejos, en sus estructuras normadoras, gestionarias y sancionarias. El concepto de institución en esta definición, se entiende como un conjunto relativamente estable de roles y relaciones, bien establecidas, con normas que refuerzan y sancionan como sistema y con mayor complejidad que una red.

4. Capital social de puente: Es una extensión del capital social en las formas antes mencionadas, pero referida a los vínculos que dan acceso a personas e instituciones distantes, tanto horizontales como verticales. Su importancia radica en que facilita el acceso a otras formas de recursos sociales, culturales, económicos y políticos, siendo un ejemplo característico de capital social de puente el que relaciona las comunidades pobres y el Estado y el que se pudiera crear y fortalecer entre la familia y la escuela.

5. Capital social societal: Se refiere al capital social de las sociedades. Al respecto, existe en debate, sí es posible hablar de este tipo de capital, en tanto, las sociedades están cada vez más segmentadas, sin embargo, las normas que una sociedad posee pueden establecer diferencias que dan cuenta de la existencia de este capital.

Otra definición de capital social es la que sintetiza Atria citado por Durston (2002, pag. 14) donde enfatiza que los diversos trabajos sobre el tema muestran que es posible distinguir dos dimensiones del concepto: una es la capacidad de movilización de determinados recursos por parte de un grupo; y la otra, es la disponibilidad de redes de relaciones sociales.

En la primera dimensión, la capacidad de movilización se relaciona con el liderazgo y el empoderamiento. En la segunda, los recursos involucran los conceptos de asociatividad y el carácter horizontal o vertical de las redes sociales, redes que pueden conformarse al interior de un grupo o comunidad, entre grupos y redes de relaciones externas. 
De esta forma, el capital social comunitario queda definido como la capacidad efectiva de movilizar productivamente y en beneficio del conjunto, los recursos asociativos que radican en las distintas redes sociales a las que tienen acceso los miembros del grupo en cuestión.

Mientras el debate teórico sobre el concepto de capital social y su posible medición continua, diversos estudios dan cuenta de la acción concreta que puede ejercer el capital social.

Kliksberg (1999) sintetiza diferentes estudios en varias áreas, demostrando la presencia y potencialidad del capital "Capital social: concepto, dimensiones y estrategias para su desarrollo",

-Knack y Keefer (1997) correlacionaron las variables confianza y normas de cooperación cívica con crecimiento económico, en varios países. Ello indicó que las primeras tienen un fuerte impacto sobre el segundo. Asimismo, sostuvieron que el capital social integrado por esos dos componentes es mayor en sociedades con menor desigualdad.

-Narayan y Pritchel (1997) trataron de relacionar el grado de asociatividad y rendimiento económico en hogares rurales pobres, descubriendo que las familias que tenían grados de participación en organizaciones colectivas, acumulaban capital social que las beneficiaba en la obtención de mayores niveles de ingreso a través de distintas vías, tales como mayor acceso a la información tecnológica y del mercado. A su vez se interesaban en mejorar los servicios públicos y se relacionaban más con el municipio.

-La Porta, López de Silanos, Shlerfer y Vishny (1997) obtuvieron correlaciones significativas entre el grado de confianza existente en una sociedad y factores como la eficiencia judicial, la ausencia de corrupción, la calidad de la burocracia y el cumplimiento de las obligaciones tributarias.

-Teachmann, Proesh y Carver (1997) indagaron la influencia del capital social en el rendimiento educativo de los niños, descubriendo una fuerte correlación entre tres indicadores dinámica familiar, lazos con la comunidad y el número de veces que un niño ha cambiado de colegio con la probabilidad de deserción. Su hipótesis es que el capital social

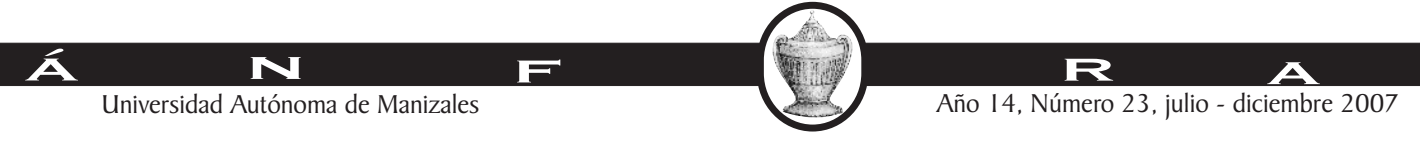


hace más productivas otras formas de capital, como el humano y el financiero.

\section{ALIANZA ESCUELA Y FAMILIA.}

De acuerdo con Norodowski, M. (1999) todo contrato entre las partes dispone derechos y obligaciones para las mismas. Y como todo contrato, también el dispositivo de alianza familia y escuela construido por la pedagogía moderna estipula que pueden hacer los padres y los maestros respecto de la educación de sus hijos y alumnos.

En lo que se relaciona con los padres estos tienen la obligación de educar a los niños en las escuelas para que se conviertan en alumnos y, por tal motivo, ponerlos a disposición de la escuela. Pero esta situación no es fácil para los niños quienes deben dejar sus actividades lúdicas y someterse a las exigencias de la institucionalidad, basadas en la imposición de una nueva autoridad adulta.

Pero igualmente esta alianza es poco productiva ya que la escuela es impositiva con la familia, además la familia cuestiona ¿qué aprenden los niños en la escuela, qué saberes, qué hábitos? ¿ pone la escuela la misma autoridad y los mismos valores establecidos en el hogar?

Desde hace ya más de un siglo es natural ver a los niños y jóvenes siendo entregados por sus padres a la escuela, sin embargo y en virtud de las resistencias relativas a las obligaciones de los padres en el dispositivo alianza, la escolarización no fue un acto natural y único, sino que tardó mucho tiempo en instalarse. Los países tuvieron que recurrir a leyes que obligaban a los padres a llevar sus hijos a la escuela y con ello garantizar la concurrencia de los niños a la escuela y como contrapartida la familia debía recibir de la escuela una mejor formación para sus hijos, es de recordar que esta alianza empieza a surgir como parte de la división del trabajo donde algunos adultos se destinarían a la formación de los hijos y los padres a trabajar para mantener la familia.

Algunos factores son comunes a la escuela y la familia, debiendo ser analizados para comprender en que contexto se dan las relaciones, estos son: organización jerárquica, reglas, cultura y sistema de creencias. 
Organización jerárquica: la estructura de estos dos sistemas presupone una organización jerárquica con diferentes tipos de límites: límites generacionales, límites jerárquicos y límites entre subsistemas. Es importante descubrir, ¿quiénes en la familia y en la escuela constituyen el subsistema ejecutivo?, ¿Quién toma las decisiones?, ¿Se toman por medio de consulta, o de imposición o no se toman?, ¿Hay reglas explícitas relacionadas con las decisiones? ¿Cómo se comunican?. Esto permitirá determinar los patrones de conducta y las diferencias entre ambos sistemas.

Reglas: En todo sistema, organización e institución existen reglas que gobiernan el modo en que las personas han de comportarse unas con otras, lo que se debe hacer y lo que no, pero también hay reglas sobre cómo se deben hacer las reglas, quién las hace y cómo se han de negociar. Las reglas rígidas e inflexibles en las escuelas se han asociado con serios problemas de disciplina en los niños y adolescentes. Daren, 1982 citado por Dowling, E. (1996) hace referencia a un proceso en el cual los niños en edad escolar absorben las reglas familiares, las contrastan con las reglas existentes fuera del sistema familiar, principalmente la escuela, y reproducen en la familia su nueva versión integrada de normas intra y extrafamiliares. Por tanto no es difícil imaginar la posición imposible en la que se puedan encontrar los niños en medio de conjuntos de reglas tan diferentes y con grados de lealtad tan diversos.

Cultura: Morgan 1986 citado por Dowling, E. (1996) describe la cultura como significado, comprensión y sentimientos compartidos. Al mencionar la cultura estamos hablando de un proceso de construcción de la realidad que permite a las personas ver y entender sucesos particulares de modo característico. Comprender la cultura nos permite entender la familia y la escuela en relación con su entorno. Llegamos a conocer y a relacionarnos con nuestro entorno de acuerdo con el sistema de creencias que guía nuestras interpretaciones y acciones.

Morgan sugiere que aprendemos las características de una cultura particular a través de la observación de modelos de interacción, lenguaje, la evolución de las normas, los distintos rituales, los valores y las actitudes dominantes. 
Schein (1985) citado por Dowling, E. (1996), sin embargo argumenta que estas características reflejan la cultura pero no su esencia. La esencia de la cultura, según él, se encuentra en el nivel más profundo de los supuestos y creencias compartidas que operan inconscientemente y definen de una manera básica, que damos por supuesta una perspectiva de la organización misma y de su entorno. Estos supuestos básicos son implícitos y guían la conducta. Por ejemplo, si en los fundamentos de la experiencia y la educación está el supuesto de que las personas son vagas por naturaleza, asumiremos que, si están sentados sin hacer nada, no pueden estar pensando, sino perdiendo el tiempo. Lo mismo sucede si en una escuela no están enseñando las tres áreas de matemáticas, lectura y escritura las familias tienden a cuestionar que los niños no aprenden nada.

Un aspecto particular de la cultura de una institución es su ethos, que hace referencia a su espíritu y tono característico.

Así mismo Dowling, E., haciendo referencia a Ruter y otros (1979) señala el modo en que las escuelas y las familias han desarrollado un ethos que está íntimamente relacionado con su carácter de organización social. Sabemos que los padres tienen expectativas académicas para sus hijos y buscan una escuela con buena reputación académica. Lo cual significa, generalmente, en la perspectiva de los padres, valores tradicionales buenos y "anticuados", énfasis en la disciplina y mucho trabajo. Las escuelas, a su vez, desarrollan actitudes y reglas que confirmen las percepciones que tienen los padres de sus ethos.

Sistema de creencias: Para que la conducta individual tenga sentido en el contexto de la familia o la escuela, es importante entender el sistema de creencias o el sistema de significado que gobierna una conducta particular, "el aprendizaje y la conducta tienen una relación recursiva o circular. Nos comportamos voluntariamente como lo hacemos, porque tenemos ciertas creencias acerca del contexto en el que nos encontramos y nuestras creencias se ven apoyadas o amenazadas por el feedback que nos reporta nuestra propia conducta" (Campbell y otros, 1988, pag. 16). Las creencias mantenidas por las familias y las escuelas han sido, generalmente apoyadas a lo largo de mucho tiempo por el contexto nacional e internacional y han llegado a constituir la

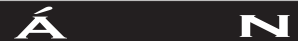

Universidad Autónoma de Manizales 
cultura de la familia u organización, es decir el modo en que se percibe y se entiende al mundo.

Cuando los padres reaccionan de una forma molesta ante una queja de la escuela por la conducta del niño, atribuyéndolo a las "malas" influencias de otros niños, quizás estén reflejando la creencia de que todas las influencias fuera de la familia son probablemente negativas. Tal vez durante mucho tiempo, algunas situaciones difíciles se han explicado buscando la fuente del problema fuera de los límites de la familia.

Del mismo modo, las escuelas tienen una cultura particular que viene determinada en parte por el sistema de creencias. Por ejemplo, puede existir la firme creencia de que aceptar o reconocer las dificultades, lo cual podría suponer ayuda externa; es reflejo de que son escuelas malas que no pueden enfrentarse a los problemas. Es la creencia de que la fuerza y la calidad se basan en la autosuficiencia para gobernar e influir en su actitud frente a cualquier intervención profesional proveniente del exterior. Una relación activa entre la escuela y la familia podría contribuir a crear un nuevo contexto en el que el problema de conducta de los niños y jóvenes se perciba de modo diferente, y dicha percepción diferente podría llevar a una creencia diferente a cerca de la situación.

En los anteriores elementos se puede notar como ambas instituciones cargadas de realidades, en ocasiones es la diversidad y contradicción lo que permite construir juntas un nuevo proyecto de vida donde estén los intereses de los niños y los adolescentes, partiendo de un conocimiento reciproco que acceda a aportar al capital social.

En la investigación "Familia, escuela y medios de comunicación ante los valores" realizada por el Instituto Nacional de Calidad y Evaluación (INCE). (1997), Con una muestra de 17.500 alumnos pertenecientes a 702 centros, públicos y privados, distribuidos por todo el territorio español, con excepción de Andalucía, se evidencian algunos resultados que ponen de manifiesto como la familia y la escuela potencian el desarrollo de actitudes y valores en ocasiones diferentes. El propósito era a partir de un cuestionario dirigido a las familias, conocer en qué medida la escuela, la familia y los medios de comunicación fomentan a juicio de los padres, determinados valores y actitudes.

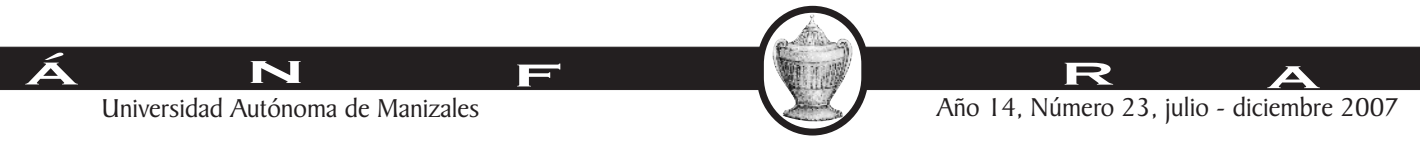


La investigación permite concluir que la familia tiene una excelente opinión de sí misma como instancia socializadora de los hijos y manifiesta al tiempo una cierta desconfianza del papel de los medios de comunicación como transmisores de valores. La valoración que los padres hacen sobre la participación de los medios de comunicación en la socialización de los niños y jóvenes es bastante negativa, sólo los valores de "respeto a la naturaleza" y "libertad personal" son fomentados de manera adecuada por los medios a juicio de las familias. La percepción negativa a este respecto aumenta con el nivel cultural de los padres y con el tamaño del municipio donde residen. Por otra parte, los padres de alumnos de centros privados son más críticos que los de centros públicos en su opinión sobre el papel de los medios de comunicación en relación con determinados valores.

En relación a la formación de actitudes, enfocadas como cualidades que los padres desean ver en sus hijos, la visión de los padres parece demasiado optimista.

Y en relación a los valores de convivencia y pautas de comportamiento manifestaron que la familia constituye el entorno donde el niño capta los valores y normas que inciden en la socialización y que la convivencia es de hecho óptima, ya que el respeto entre sus miembros, la adaptación a las circunstancias económicas y el diálogo aparecen claramente valorados.

El orden de prioridades en relación con aquellas dimensiones de la educación que afectan a todo el currículo (los llamados temas transversales) no es el mismo para la familia que para la escuela. En efecto, los padres parecen encontrarse especialmente preocupados por el problema de las drogas y su prevención y bastante poco por la cuestión de la educación para el consumo artificial, dato este último que no deja de ser en gran medida contradictorio y quizá por eso desalentador. Menor importancia todavía parece conceder la familia a la educación religiosa. Los padres consideran, en cambio, que los centros educativos prestan especial atención a la educación para la paz, y a la educación moral y cívica.

En relación a imagen de los hijos, el $84 \%$ de los padres piensa que sus hijos son "poco" o "nada" agresivos y el $60 \%$ que son "poco" o "nada" 
consumistas. Este dato se deriva de las respuestas dadas a preguntas sobre la conducta de los hijos. Dado que las situaciones conflictivas han crecido en el conjunto de la sociedad, cabría pensar que los hijos presentan en el entorno familiar, una imagen dulcificada y que, en este contexto, existe un clima de sobreprotección apreciable de los hijos por parte de los padres.

Familia y escuela desempeñan roles educativos complementarios, que con frecuencia se superponen, por lo que necesitan encontrarse para conversar, delimitar sus espacios de autonomía y precisar sus tareas compartidas.

La alianza entre escuela y familia permitiría lograr mayor coherencia en las metas para el desarrollo afectivo, cognitivo, social y valórico de las personas. Dicha alianza contribuye a mejorar significativamente la calidad de los aprendizajes escolares.

\section{LA ESCUELA.}

La escuela no siempre dependió de la institución escolar, durante muchos siglos la humanidad ha utilizado mecanismos diferentes a la escuela para reproducir sus valores y sus maneras de pensar, y es así, como en un principio existían un conjunto de sensibilidades y ritualidades que no tenían que ver con el maestro, el libro, un salón, unos estudiantes recibiendo clase de español o matemáticas.

Maillo, A. (1964) sostiene que la enseñanza primaria, en cuanto iniciación al manejo de los símbolos en que la cultura encuentra primordial expresión, ha existido siempre, desde que el hombre empezó a vivir su existencia civilizada. La escuela, en cambio por lo menos en sus formas últimas y más evolucionadas es una creación de la modernidad, para que la escuela surgiera tuvo que someterse la enseñanza a un doble proceso de profesionalización y de institucionalización. A la actividad docente familiar, en la que el padre, actuando de maestro, comunicaba a sus hijos el conjunto de evidencias necesario para que el vivir no fuese una tarea desprovista de sentido (mitos, normas, técnicas) se reemplazó por la enseñanza de un profesional, cuantitativamente superior, a causa de una elaboración cultural más amplia, y técnicamente más adecuada. Cantidad de 
contenido y superioridad didáctica son las pautas que definen el proceso de delegación de responsabilidades educativas de la familia a la escuela.

Históricamente, el grado primario es el último surgido en la evolución de la enseñanza, como actividad docente dotada de significación propia y por ello mismo, merecedora de encuadrarse en el marco de una institución jurídicamente delimitada y protegida.

Durante la edad media, la enseñanza institucionalmente reconocida se reduce al grado medio-superior, constituyendo una realidad jurídica y funcional única: La universidad, hija de un proceso de integración de actividades docentes dispersas, cuyo estudio, todavía no agotado, tiene el mayor interés sociológico y pedagógico.

"La enseñanza elemental existía sin duda, porque era indispensable dar una preparación a los niños que habían de acceder a la facultad de artes, procedente de los actuales institutos de enseñanza media. Pero tal iniciación reducida a poco más que al manejo de los símbolos literales y numéricos mediante la lectura, la escritura y el cálculo, los cuales eran comunicados por cualquiera que los poseía, aunque generalmente era por clérigos, de algún modo era considerada como objetivo de la institución, aunque no fue así considerada por la familia, la sociedad, ni por el Estado" (Maillo, 1964).

En rigor, el mismo aspecto profesional era sumamente débil, no sólo por la falta de dedicación exclusiva a la docencia de la primaria, sino porque el componente técnico, apenas existía y más aún como rutina.

Tanto en el campo de la teoría como en el de la práctica, el grado primario comienza a sentir la necesidad de institucionalizarse en el renacimiento. La escuela primaria es una creación de la modernidad y debe al espíritu del humanismo renacentista dos de sus caracteres más importantes: a) el ámbito popular, esto es, de participación de todos en los beneficios que de su acción podían derivarse, y b) la intervención progresiva del Estado, cada día más dispuesto a convertirse en rector de la vida social a partir de finales del siglo XV, en cuanto se relacionaba con la misión y fines de la escuela.

La enseñanza primaria, estrictamente concebida como una propedéutica de la secundaria durante toda la edad media, se daba

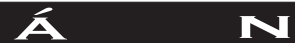

Universidad Autónoma de Manizales 
solamente a los hijos de los miembros de clases socialmente elevadas, aunque la iglesia católica, a cuya sombra benéfica nacieron todas las actividades y grados docentes, luchó siempre contra el "espíritu de linaje", de origen germánico, y practicó un tipo de democrática selección en los candidatos a los estudios sagrados. Sin embargo, el predominio social de un derecho eminentemente discriminador, basado en el cuidado de lo diferencial, que desembocaba en el "privilegio", engendró en el renacimiento, por contragolpe, el anhelo de una enseñanza primaria destinada a los humildes.

Para mediados del siglo XX la escuela se definía en términos sociológicos, como un grupo convencional, ya que no obedece a necesidades de su naturaleza, sino a exigencias de lo cultural, su función desde el punto de vista político, ha sido hasta ahora la nacionalización de las conciencias de las nuevas generaciones, procura ante todo la socialización de los niños que han de tomar un día el relevo en las funciones y tareas de la sociedad, de las pautas y normas que traducen los valores al grupo cultural al que pertenecen, cuyos símbolos esenciales constituyen el alfabeto fundamental de la educación.

En un principio la escuela era vigilante de la actividad escolar individual y poco se preocupó por el trabajo colaborativo o en red que favoreciera la mirada multidisciplinaria en la formación integral del niño, de allí que Dewey citado por Maillo, A. (1965) atacara la escuela ya que está consideraba la interayuda como un "pecado escolar".

Posteriormente surge el criterio de escuela para la comunidad actuando como instrumento para la promoción humana, de esta modalidad se distinguen dos características esenciales según Dewey, una es que la escuela desea especialmente la cooperación de los padres para crear el tono moral sano que haga innecesario recurrir a motivaciones inferiores e indignas para regular la conducta y el cultivo de un tono democrático que se haga presente en la vida social de la escuela en conjunto y no solamente en un círculo o grupo dentro de ella; y segunda,es la de vincular profundamente la escuela a la comunidad local en la que opera como instrumento de mejoramiento global, es decir, de instrucción y de formación de niños y adultos.

En la actualidad se hace palpable ver como la escuela sigue estando sola a espaldas del mundo real, externo a las instituciones, sin contar con el

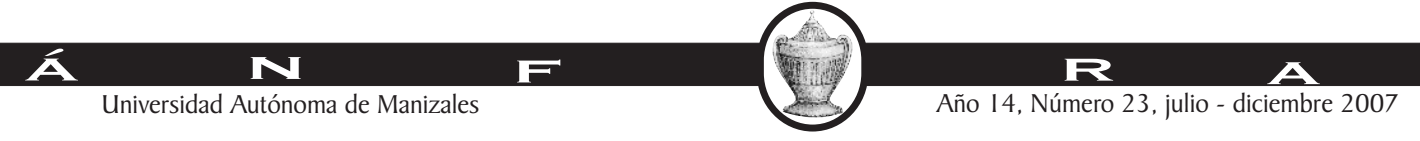


trabajo colaborativo de la familia, institución igualmente poderosa en la educación de los niños, ni tampoco con la sociedad civil, la comunitaria donde el niño se desenvuelve y hace relaciones con sus pares de amigos.

Los viejos patrones educativos no le sirven hoy a la escuela para educar. A merced de los vientos del autoritarismo de ayer y del permisivismo actual, a veces, deja hacer... porque no sabe qué hacer. Encerrada en una burocracia asfixiante, se le hace difícil vivir el sentido comunitario que, proclaman los documentos que la rodean y le exigen los nuevos valores democráticos. Siente la presión de las demandas que van más allá de su tradicional función transmisora de conocimientos y no se siente preparada para afrontarlas.

Sin embargo el concepto mismo de escuela ha evolucionado, en 1990 Fernández Enguita, la definía como "Una institución social especialmente creada como administradora de conocimientos y habilidades, con un espacio físico concreto, con una distribución del tiempo particular en su interior, y una serie de normas. Es el lugar de paso obligatorio para constituirse en un adulto responsable y donde, además, se aprenden las pautas de comportamiento socialmente aceptadas. En tanto institución, la escuela como un componente del todo social tiene una función de conservación y reproducción del equilibrio del sistema" y hoy se percibe de acuerdo a Sapiains, A; Zuleta, P. (2001) como una institución en la que se depositan la responsabilidad y la confianza para que las nuevas generaciones de la especie humana adquieran o desarrollen conocimientos y habilidades necesarios para desenvolverse en la sociedad. La escuela enseña a nuestros niños y jóvenes todo lo que es importante que sepan y no pueden adquirir en el seno de su familia, agregando como componente fundamental la evaluación.

Y con relación al proceso de escolarización propio de la institución escolar, se consideran cuatro ideas fundamentales para comprender y desarrollar el concepto: 1 . Las escuelas no pueden ser analizadas como instituciones separadas del contexto socioeconómico en el que están situadas. 2. Las escuelas son sitios políticos involucrados en la construcción y control de discurso, significado y subjetividades. 3. Los valores del sentido común y las creencias que guían y estructuran las prácticas en la sala de clases, no son universales a priori, sino que son

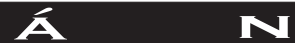

Universidad Autónoma de Manizales 
construcciones sociales basadas en supuestos normativos y políticos específicos. 4. La socialización dada en la escuela no es un simple vehículo de transmisión del orden social, sino agencia de control social que funciona para ofrecer formas diferenciadas de enseñanza a diferentes clases sociales (Apple, citado por Soto, 1996).

En la actualidad los rituales han cambiado notablemente y se pasó de educar para creer en Dios, ser obediente y salvar las vidas del pecado a una escuela con pensamiento práctico y una lógica formal. (Martín Barbero J. 2004 en conferencia en Manizales). Pero esta última tiene hoy unas nuevas tendencias que la están llevando a tramitar a la sociedad del conocimiento.

La escuela se inició en un marco de referencia donde se concebía la socialización primaria y secundaria. La socialización primaria dada por la familia, como aquella que asume la responsabilidad de formar los cimientos de la personalidad de los miembros de la sociedad, la secundaria cuando se transmite el modelo cultural existente.

Actualmente se hace notable como estos dos procesos de socialización han cambiado por las formas de transformación social y cultural que vienen provocando una crisis en la identidad de la escuela, la familia, la calle y los grupos en general, hoy vemos pues, como otros agentes han asumido la socialización del individuo, entre ellos los medios masivos de comunicación que han homogenizado la sociedad, han hecho que las culturas estén perdiendo su propia identidad y las nuevas políticas de revolución educativa entre otros aspectos, que han hecho que la escuela sea sólo un facilitador del proceso de socialización.

Es evidente cómo la función que actualmente ejerce la escuela se está quedando obsoleta desde que se dio origen a los medios modernos de comunicación, desde entonces se insiste en la necesidad de enfrentar cambios radicales en la educación formal de las nuevas generaciones del conocimiento.

Manejar la incertidumbre es una de las funciones de los nuevos agentes socializadores, ya que en la actualidad el joven se ve obligado permanentemente a tomar decisiones frente a variadas circunstancias y lo más importante a informaciones cada vez más numerosas y 
cambiantes. La escuela, por esto, debe formar un sentimiento de cohesión, tolerancia a la diversidad, la confianza y espíritu de cooperación cívica.

Rodríguez, E. $(2002,67)$ Manifiesta que en la educación de los jóvenes todos cuentan padres, docentes y la comunidad, resulta vital que los actores participen hoy en nuevas dinámicas a impulsar, hoy no se puede seguir viendo la institución educativa como único actor y los demás sólo como convidados de piedra que deben ayudar en su casa para no molestar en el establecimiento educativo. Hoy más que nunca no se puede reducir el papel de la educación a uno de sus componentes:la enseñanza, dejando de otro lado el aprendizaje, dicho de otro modo el aprendizaje es lo relevante y la enseñanza pasa a ser un aspecto puramente instrumental.

¿Pero cómo ven los jóvenes la escuela? En una investigación realizada por Sapiains, A; Zuleta, P. (2001, pág. 61-62) en Chile, sobre las representaciones sociales acerca de la escuela en jóvenes desescolarizados (13 jóvenes que tenían entre 8 y 9 años de escolaridad) los investigadores formulan dos núcleos figurativos, a través de los cuales se logra evidenciar que no vasta el grado de escolaridad sino los años que en ella se está para lograr un grado de representación de lo que ella es:

-El primer núcleo: la escuela como un derecho; necesaria e imprescindible. La construcción del primer núcleo figurativo surge desde el discurso de un grupo de los jóvenes entrevistados; aquellos que vivencian su condición de desescolarizados asociada a sentimientos de pérdida en todos y cada uno de los ejes en torno a los cuales se articula esta representación social de la escuela.

En el discurso de este grupo de jóvenes, la escuela aparece como un espacio social validado; tanto en sus formas, como en sus funciones, y al mismo tiempo como un espacio social validador de los jóvenes como individuos, en tanto desempeñan el rol de estudiante. En esta medida, las relaciones sociales que se establecen en la escuela, además de tener un fuerte componente afectivo, son vividas como legítimas en tanto se dan en el seno de la institución. Así, no es lo mismo un compañero de curso que un vecino desescolarizado, ni jugar un videojuego en la sala 
de computación de la escuela, que en los Cibercafé de la esquina de la casa, aunque las actividades y motivaciones en ambos casos sean las mismas.

La escuela aparece como el único lugar posible para obtener una identidad juvenil positiva y reconocida, igualándose, en la experiencia de este grupo de jóvenes, la condición juvenil con la condición de estudiante. Del mismo modo, las relaciones sociales establecidas entre este grupo de jóvenes y los adultos significativos en el espacio escolar, está mediada por la atribución dada a la escuela como la única institución dueña de los saberes y de los poderes necesarios para desempeñar el rol educador en la sociedad.

En este contexto, son los adultos significativos del medio escolar los que encarnan estas atribuciones; lo que se traduce en la legitimación y consecuente aceptación de estilos de relaciones interpersonales, que en nuestras escuelas se encuentran preferentemente marcadas por la jerarquía y el autoritarismo, constituyéndose estos componentes, muchas veces, como imprescindibles y demandados por alumnos y apoderados (los que exigen una disciplina más severa) como garante de la buena formación de los niños y jóvenes.

La formación disciplinaria represiva y coercitiva, aun cuando sea vivida como positiva y necesaria, tiene un claro límite en el discurso de los jóvenes: la agresión física como castigo. A pesar de todas las atribuciones otorgadas a la escuela para formar y educar a sus estudiantes, el uso de la violencia física es fuertemente rechazado, y por ende, excluido de la potestad otorgada a la institución. Estas relaciones interpersonales entre jóvenes y adultos significativos tienen su manifestación más importante en el plano instruccional, el que además es el temporalmente más significativo; en éste, la relación se ve reducida a la entrega de conocimientos y al mantenimiento de un clima que lo permita, siendo la profesora o el profesor el ser omnisapiente que ha de procurar el traspaso de conocimientos desde una posición de saber hasta la posición de los ignorantes.

La escuela, en esta representación social, continúa siendo la institución garante de las aspiraciones futuras; continúa siendo el camino único y apropiado para el acceso a mejores condiciones de vida, y el único 
espacio social capaz de formar personas que se integren y sean útiles a la sociedad.

- El Segundo núcleo: la escuela como obligación; controladora y descontextualizada.

La construcción del segundo núcleo figurativo surge a partir del discurso de un grupo de jóvenes que manifiesta sentimientos de incomodidad, desagrado y malestar asociados a la temática escolar en general, y a la institución escuela en particular. Esta representación social da relevancia, en términos positivos, de manera exclusiva al plano vincular y afectivo con el grupo de pares; entendiendo por esto la dinámica juvenil que en el escenario escolar se desarrolla y en cierto modo, a pesar de las normas y la vigilancia, la escuela posibilita.

Más, lo realmente significativo resultan ser los sentimientos negativos asociados a los ámbitos disciplinarios, instruccional, vincular con los adultos e instrumental. Se trata de un malestar más emotivo que reflexivo, que sitúa a la escuela como un espacio que les resulta ajeno, impropio, impuesto y al que no logran adaptarse.

Se trata de una institución en la que las relaciones sociales, particularmente con los adultos significativos, son fundadas en la obediencia y el respeto a la autoridad; respeto muchas veces incomprendido y otras tantas intolerado; pues se trata de una disciplina que les resulta impropia, que prescribe y proscribe comportamientos, que establece sanciones y procedimientos para resolver conflictos (si es que los resuelve) de manera prioritaria y descontextualizada de la realidad psicológica, social, económica y cultural de los jóvenes. En esta medida, la escuela es vivida por los jóvenes como un espacio inalterable sobre el cual no tienen ninguna injerencia y que ofrece sólo dos alternativas: adaptarse o no adaptarse.

La escuela, en esta representación social, entrega conocimientos y establece metodologías que resultan poco significativas, aburridas y desmotivantes. La escuela se vivencia como un espacio poco gratificante en lo afectivo, inútil para lograr un mejor presente y futuro laboral, y coartador de la expresión e iniciativa juvenil. 
En síntesis, la representación social de la escuela en los jóvenes se funda en un sentimiento de malestar que, en lugar de movilizar acciones y reflexiones, conduce a reafirmar la condición de desescolarizado; pues, ni por un motivo ni por el otro visualizan la posibilidad de obtener mejorías en su condición de vida mediante la reescolarización.

\section{LA FAMILIA.}

Para la época de los setenta, Flandrin, J. en su libro orígenes de la familia moderna, advertía que el termino "familia significa realidades diversas", y en sentido amplio definía que era el conjunto de personas mutuamente unidas por el matrimonio o la filiación; o aún la sucesión de individuos que trascienden unos de otros. Pero el término tiene un sentido más estricto de lo que definen los diccionarios pues las épocas han apropiado diferentes formas de ser y recrear la familia, es así que al definirla como "las personas emparentadas que viven bajo un mismo techo", fue fácil de asimilar en el siglo XIX y parte del XX ya que en esta época solo vivían el padre la madre y los hijos y por ende la familia estaba conformada por este grupo de personas, pero no ocurrió en el siglo XVI-XVIII, la familia evocaba mucho más a menudo, por un conjunto de parientes que no tenían residencia común; y generalmente designaba también un conjunto de copresidentes que no estaban ligados necesariamente por vínculos de sangre o de matrimonio.

Pero finalmente la familia del siglo XX con la que creció el capitalismo, nuclear y patriarcal con pequeños ajustes está en proceso de disolución total. Existe una crisis radical de la pareja, hecha para parir hijos y de fidelidades eternas, o mejor, cambió el imaginario de familia y se transformó el estatuto de la mujer, la cual está innovando en espacios donde antes en América Latina no tenía entrada, y específicamente en Colombia ha tenido un reconocimiento especial desde lo empresarial hasta en lo educativo.

De otro lado los cambios en la conformación familiar, su disminución en el número de hijos, el aumento de uniones libres, de madres solteras, de niños que viven con sus abuelos, de mujeres que desean formar familia pero sin hijos, la ausencia de la familia extensa, la vinculación de la mujer al trabajo, han impulsado una delegación de la responsabilidad 
de socialización primaria en otros agentes o espacios diferentes a la familia.

Los avances científicos y tecnológicos han supuesto cambios muy rápidos. Se suceden de forma vertiginosa, no dando lugar a que el hombre pueda interiorizarlos y adaptarse a las nuevas exigencias que estas transformaciones van imponiendo al mundo de la cultura, mucho más lento en su evolución. Estos cambios, que afectan la educación familiar, se sitúan en dos planos: interno y externo:

Interno: La familia necesita un marco de referencia para guiar, orientar y educar a sus hijos, porque está sumergida en un mundo cambiante, cuya inestabilidad e incertidumbre fomenta inseguridad y miedo, además, se encuentra confundida; las viejas creencias, los valores vividos y la educación recibida no le sirve para educar a su generación actual.

Externo: La familia se encuentra en medio de contrastes ante los cuales se siente sobrepasada y se pregunta cómo responder a las demandas de sus hijos que están fuera de los esquemas de sus propias experiencias y vivencias.

En este contexto, la familia tradicional aparece desdibujada, ha perdido sus antiguos puntos de sustentación, se han venido abajo los grandes pilares que sostenían sus creencias y cimentaban, los roles atribuidos a los diferentes miembros de la familia, por ejemplo: el hombre, en la figura del padre, no representa la autoridad como pilar de fuerza y poder; la mujer, en la figura de madre, no representa el amor como pilar de sumisión y abnegación y la sexualidad, no representa lo puro y misterioso como pilar de reproducción.

Históricamente la Familia ha permanecido bastante ausente en la vida y misión de las escuelas, tanto es así, que hasta el día de hoy se enfrentan serias dificultades para contar con su presencia y aporte en el proceso educativo y pastoral que están desarrollando sus hijos. Por otra parte, sin duda, las comunidades educativas no siempre han estado suficientemente abiertas a esta corresponsabilidad, ya sea por temores, por malas experiencias o por no tener mayor claridad al momento de establecer metodologías y formas adecuadas de convocatoria y 
participación. Lo anterior, es aún más preocupante cuando se suma el hecho que en general los padres varones tienden a autoexcluirse de esta responsabilidad, considerándola equivocadamente como algo propio de las madres.

Hasta hace algunos años, la tarea fundamental de la familia en cuanto primera y principal responsable de la educación de sus hijos, se llevaba a cabo en casa en un hogar estable, y en donde los grandes valores y principios a desarrollar en la prole, eran compartidos, promovidos y defendidos en general por toda la sociedad, favoreciendo así no sólo la claridad de los fines educativos de los padres, sino también la claridad respecto a ciertos aprendizajes.

Como lo afirma Théry 1996 citado por Tedesco "la familia contemporánea asume la forma de una red de relaciones que, en lugar de ser responsable de transmitir el patrimonio cultural y moral de una generación a otra, tiende ahora a privilegiar la construcción de la identidad personal".

Aquí se puede ver como la familia al igual que la escuela han sido objeto y sujeto de diversos cambios, para lo cual deben responder y una posibilidad de afrontar estos cambios es a través del trabajo en conjunto, propiciando una red social donde se privilegie la confianza, la cooperación y la reciprocidad.

\section{ALIANZA FAMILIA Y ESCUELA COMO FUENTE DE CAPITAL SOCIAL.}

Pero ¿ cuál es la función que debe designarse a la familia y a la escuela cuando la "transmisión" en una sociedad hoy es percibida como algo obsoleto, sin utilidad para el mundo, pues todo tiende a ser libre y volátil y más cuando las relaciones entre la escuela y la familia no han superado el mínimo contacto hacia un trabajo colaborativo?, la respuesta es, la escuela y la familia deben fortalecer sus relaciones de tal suerte que les permita preocuparse por la formación de un núcleo estable, de un marco de referencia en relación a la cultura, que le permita a los niños y los jóvenes enfrentar los cambios constantes a los cuales se ven sometidos por la nueva producción cultural que hace que diariamente las transformaciones se vivan como una ruptura con el

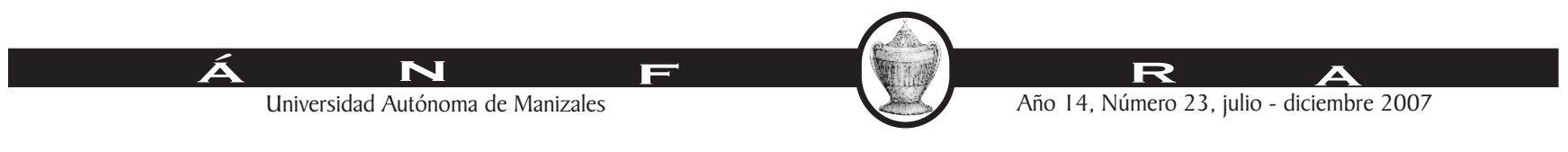


pasado, de allí que se pierda la idea de continuidad histórica según Tedesco (2003).

Es importante resaltar que independiente de la estructura familiar que exista,ésta debe cumplir un papel indispensable en la formación del individuo y en la continuidad de la sociedad, se puede ver como la socialización de las nuevas generaciones implica la adopción de nuevos estilos formadores que permitan al niño transitar por las diferentes etapas del ciclo vital.

Benavides, J; Gálvez, G y otros(2000) en su documento "Proposiciones para promover relaciones colaborativas entre familia y escuela" manifiestan que son los grupos familiares más pobres son los que necesitan fortalecer en mayor dimensión la alianza pues hay gran número de parejas jóvenes, cuyas necesidades aumentan aceleradamente a medida que van teniendo más hijos y que estos van creciendo; generalmente ambos padres trabajan, con largas jornadas laborales, sin lograr ingresos suficientes para satisfacer las necesidades de la familia y reduciendo a un mínimo el tiempo compartido en el hogar. Son frecuentes las familias monoparentales, en las que uno de los padres está a cargo de la crianza de los hijos, sin tener una pareja estable. Encontramos también familias reconstituidas, en las cuales, además de los hijos compartidos, cada miembro de la pareja puede tener hijos de una unión anterior. $Y$ muchas situaciones de niños que residen, temporal o permanentemente, con abuelos, tíos o padrinos.

Estas familias consideran que la educación escolar modificará la futura situación de sus hijos y la transforman en la gran expectativa. Por ello le demandan todo: excelencia, atención preferencial, afecto y cariño para sus hijos.

Por su parte, la escuela tiende a ver a los grupos familiares como beneficiarios y objetos del proceso educativo y no como sujetos o protagonistas de éste. Le cuesta aceptar la diversidad de las familias con que trabaja: las que no corresponden al modelo nuclear biparental son consideradas mal constituidas, enproblemadas e incompetentes para dar el apoyo que los niños requieren.

Revalorar esta relación significa un largo proceso de introspección y de apertura a la comprensión del otro. Si ambos actores objetivan los

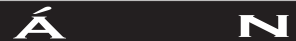

Universidad Autónoma de Manizales 
ámbitos en que se valoran o critican es posible que, conocido el campo de las apreciaciones mutuas, se pueda llegar a acuerdos básicos en la relación.

Benavides, J.; Gálvez, G. y otras (2003), elaboran sobre las demandas reciprocas entre la escuela y la familia como se presenta a continuación.

\section{¿Qué le demanda la familia a la escuela?}

-Eficiencia en el servicio educativo. Las familias piden una buena base de conocimientos y experiencias que acrediten a sus hijos para continuar con éxito sus estudios o entrar al mundo laboral en óptimas condiciones.

- Formación sólida y diversificada.. La familia busca que la escuela prepare a sus hijos para enfrentar responsablemente las dificultades y riesgos de la vida social. Quieren una escuela consejera y orientadora.

-Trato cálido y deferente. Los padres esperan trato personalizado para sus hijos, que los profesores los consideren como personas individuales: desean manifestaciones de calidez, cariño, preocupación y protección.

Sin embargo de acuerdo con la ley general de la educación en Colombia (115 de 1994) en su artículo 13, el objetivo primordial de todos y cada uno de los niveles educativos es el desarrollo integral de los educandos mediante acciones estructuradas encaminadas a:

-Formar la personalidad y la capacidad de asumir con responsabilidad y autonomía sus derechos y deberes; proporcionar una sólida formación ética y moral, y fomentar la práctica del respeto a los derechos humanos; fomentar en la institución educativa, prácticas democráticas para el aprendizaje de los principios y valores de la participación y organización ciudadana y estimular la autonomía y la responsabilidad; desarrollar una sana sexualidad que promueva el conocimiento de sí mismo y la autoestima, la construcción de la identidad sexual dentro del respeto por la equidad de los sexos, la afectividad, el respeto mutuo y prepararse para una vida familiar armónica y responsable; crear y fomentar una conciencia de solidaridad internacional; desarrollar 
acciones de orientación escolar, profesional y ocupacional; Formar una conciencia educativa para el esfuerzo y el trabajo, y fomentar el interés y el respeto por la identidad cultural de los grupos étnicos. Pero estos retos no los pone la familia los coloca la misma institucionalidad educativa pues los padres rara vez puede opinar sobre estos importantes beneficios para los escolares.

\section{¿Qué le demanda la escuela a la familia?}

- Apoyo en exigencias rutinarias. La escuela busca que la familia garantice el cumplimiento de aspectos formales: adecuada presentación personal, asistencia y puntualidad, cumplimiento con los útiles y cuotas, asistencia a reuniones de padres y citaciones personales, entre otros.

- Apoyo en el trabajo escolar diario. Reforzar los contenidos trabajados en clase, proveer a los niños de múltiples materiales de consulta, cumplir con las tareas, fomentar hábitos de estudio.

-Adultos acogedores con los niños. Los docentes piden a los padres afectividad en la relación con sus hijos, pues sienten que les dedican poco tiempo y que ponen poca atención a sus preocupaciones. Quisieran que ellos fomentaran: paseos, conversaciones, juegos, cariños, etc.

Aquí igualmente la ley general de la educación en Colombia (115 de 1994) en su artículo 7, asume la familia como núcleo fundamental de la sociedad y primer responsable de la educación de los hijos, hasta la mayoría de edad o hasta cuando ocurra cualquier otra clase o forma de emancipación, le corresponde por tanto: matricular a sus hijos en instituciones educativas que respondan a sus expectativas, para que reciban una educación conforme a los fines y objetivos establecidos en la Constitución, la ley y el proyecto educativo institucional; participar en las asociaciones de padres de familia; informarse sobre el rendimiento académico y el comportamiento de sus hijos, y sobre la marcha de la institución educativa, y en ambos casos, participar en las acciones de mejoramiento; buscar y recibir orientación sobre la educación de los hijos; participar en el Consejo Directivo, asociaciones o comités, para velar por la adecuada prestación del servicio educativo; contribuir solidariamente con la institución educativa para la formación de sus hijos, y educar a sus hijos y proporcionarles en el hogar el ambiente adecuado para su desarrollo integral. Además en el

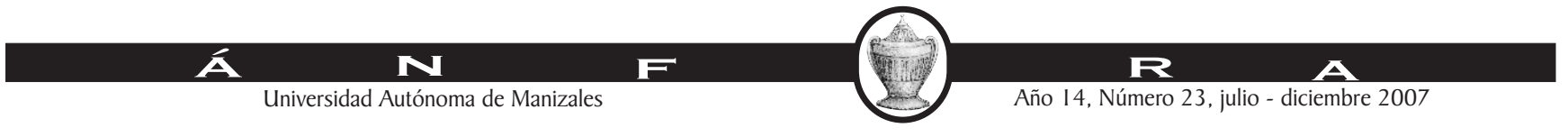


artículo 4, la misma ley le pide a la familia velar por la calidad de la educación.

\section{¿Qué le pide el contexto a la escuela y a la familia?}

Son dos los marcos de referencia que según Tedesco (2003) se deben formar en los estudiantes: el marco cognitivo (aprender a aprender) y el marco cultural (aprender a vivir juntos).

En este contexto "tienen éxito" aquellos que han desarrollado un sistema de predisposiciones apto para decidir en la incertidumbre, cambiar permanentemente de preferencias, mantener su seguridad básica aun cuando cambien radicalmente las circunstancias, ser uno mismo mientras el mundo cambia, etc. El resultado es un individuo escindido, atravesado por contradicciones, sin un sistema ontológico de seguridad básica bien establecido" (Tenti, 2001citado por Tedesco). Es este sujeto escindido quien tiene la responsabilidad de socializar a sus hijos, una responsabilidad cada vez mas compleja y con menos recursos para hacerle frente.

Esta redefinición de las formas de socialización tiene implicaciones para el caso de los adolescentes en el momento de salida de la familia hacia el grupo de pares, hacia una relación autónoma con otras instituciones o con la comunidad en general, pues esta separación supone un enfrentamiento con las elecciones predeterminadas por las familias, que al final del camino podrán ser recuperadas, transformadas o desechadas.

La situación de las familias es más compleja frente a sus hijos adolescentes a partir de que los espacios alternativos de pertenencia pueden fortalecer su transición hacia la vida adulta, proveyendo una inserción social en la escuela y en el mercado de trabajo, dejando de ser opciones atractivas en la actualidad. Compiten con ellas otras instituciones tradicionalmente desvalorizadas, como es el caso visible de los circuitos de exclusión, pobreza y la ilegalidad.

¿Qué pueden hacer familia y escuela ante esta situación?. La alianza entre escuela y familia permitiría emprender de manera coordinada un camino que consolide una nueva concepción de la educación, desde una perspectiva comunitaria real donde el verdadero protagonista sea el niño y el joven.

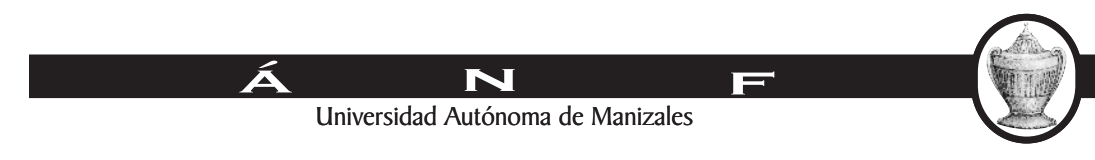


¿Cómo? Este objetivo exige la elaboración de un proyecto educativo común entre familia y escuela. Analizando y reflexionando la realidad sociohistórica en la que están inmersas y tratando de responder al tipo de educación que quieren dar a las nuevas generaciones y el tipo de hombre que quieren formar, así como en los medios e instrumentos que han de utilizar para lograrlo. Este análisis implica tener en cuenta algunos contrastes de la sociedad actual y por tanto de una participación de primer y segundo nivel (no solo de fines utilitarios de colaboración en tareas sencillas sino que recoja sus necesidades, inquietudes y recomendaciones, a fin de enriquecer la propuesta educativa) por parte de los padres en la escuela como lo propone García, M.C.(2003).

\section{¿Cómo fortalecer la relación entre familia y escuela?}

Son múltiples y diversas las acciones que se pueden desarrollar desde todos los niveles del sistema educacional para incentivar el acercamiento con la familia y mejorar la calidad de las interacciones entre ésta y la escuela. Para ello propongo algunas acciones en los ámbitos de la escuela y la familia.

A nivel de las escuelas, apoyada en diferentes autores, propongo:

-Espacios de reflexión-acción de padres, docentes y directivos. Los talleres de Profesores son una buena instancia para que profesores y directivos reflexionen juntos sobre los estilos de relación que establecen con las familias, explicitando sus expectativas y temores al respecto. Al tenor de la reflexión, podrán determinar pequeñas o grandes acciones que faciliten el acercamiento: tales cómo hacer reuniones de padres más atractivas, una redacción adecuada de las comunicaciones escritas, la definición de actividades en la escuela en las que puedan participar los padres, la forma como se manejan los reclamos y qué hacer con los padres que nunca van a la escuela, etc.

- Conformar un Equipo de Gestión Escolar que contemple acciones que tiendan a incorporar a representantes de los padres e invitarlos a participar en la definición o reformulación del Proyecto Educativo y en la del plan de trabajo anual de la escuela, dándoles derecho a opinar en la definición de criterios y normas de convivencia, etc. Igualmente se pueden realizar diagnósticos participativos sobre las necesidades de los 
niños y los jóvenes de tal manera que las planeaciones se hagan sobre la base de realidades propias y no sobre los supuestos de los medios de comunicación, un ejemplo de lo que se podría fomentar sería la propuesta de la asignatura juvenil como la que se realiza en los liceos de Chile (aporte de CIDPA a la educación media en los liceos), que busca el conocimiento de la realidad juvenil y la implementación de propuestas innovadoras donde los jóvenes vean reflejados sus problemas y realidades. "La Asignatura Juvenil es una propuesta que busca potenciar el consejo de curso como un espacio de participación y formación social y personal de los jóvenes. Su sentido principal es que puedan conversar sus problemas, intereses, aspiraciones y puedan construir sus propias respuestas a partir de la vivencia de ser joven y estudiante". (www.asignaturajuvenil.cl). Lo innovador sería que tanto los profesores como estudiantes y padres de familia pudieran programar las necesidades de formación transversales en los currículos.

-Acercamiento en los espacios habituales. En lo que se refiere a las reuniones de padres es urgente innovar incorporando nuevos temas; por ejemplo: comentar los logros y dificultades del curso, informar sobre los avances en el plan de estudio, abordar los desencuentros entre padres y profesores, etc. Para generar un clima de mayor horizontalidad y calidez se recomienda: poner las sillas en círculo, exponer los trabajos de los niños en los muros, empezar y terminar con una dinámica grupal que facilite los encuentros. Sólo al final, dejar un tiempo para las informaciones, cobro de cuotas y reclamos. Y por qué no, preparar algunas reuniones con los propios niños: que sean ellos y el profesor los que le pongan el ambiente, el contenido y la dirección al encuentro.

-Espacios de recreación y celebración. Organizar actividades de mejoramiento del espacio escolar y de recolección de dinero en beneficio de los cursos, administrando las ganancias de común acuerdo entre padres y escuela: éstas pueden resultar actividades de gran convocatoria. También, potenciar y aprovechar la preparación de los eventos de fiestas de fin de año, etc., como instancia de trabajo conjunto entre padres, niños y profesores de cada curso.

-Participación de los padres al interior de las aulas. Abrir espacios para que los padres comuniquen sus saberes a los niños: lo que hacen en sus trabajos, tradiciones familiares, enseñarles algo práctico como cocinar, 
manejar determinadas herramientas, implementar juegos de su infancia, etc. Otro importante aporte puede ser el de apoyar las actividades escolares: incentivarlos a que los acompañen en salidas y ayuden en la sala de clases. Persuadirlos de que su presencia y participación provoca un importante impacto en la subjetividad de los niños y predispone a ambos a entregarse a una experiencia de aprendizaje extraordinaria.

-Espacios informativos y formativos. Organizar encuentros para discutir los nuevos Planes y Programas. El conocimiento que los padres desarrollen sobre las orientaciones de las reformas educativas facilitará la tarea de los profesores. Abrir espacios de conversación a nivel de curso con orientadores, profesores jefes y/o profesionales de las escuelas sobre temas que preocupan a los padres, como los relativos a los objetivos escolares Centrar las conversaciones en las dudas y temores para enfrentar las problemáticas y en las herramientas para manejarse mejor.

- Cultivar áreas de interés de los padres. Ofrecer espacios para que los padres convoquen a otros padres en torno a actividades o temas que sean de su propio interés, tales como talleres (folklore, cocina, gimnasia, etc.), regularización de estudios, aprendizaje de técnicas, como computación u otras. Estas actividades son particularmente importantes para las familias de sectores pobres, cuyas carencias económicas interfieren las posibilidades de desarrollo de sus intereses. Su duración dependerá de la disposición de los padres y de los recursos disponibles.

Es pues posible y necesario involucrar a la familia en la construcción de las instituciones educativas. La apropiación del espacio educativo escolar implica la participación de la familia en su totalidad, con sus códigos, dinámicas, conocimientos, mitos, creencias y todo lo relacionado con su mundo familiar. Sólo de este modo se puede establecer un diálogo real que permita enriquecer el diseño de planes y programas de estudios, metodologías y el proyecto educativo de la escuela, estableciendo las condiciones necesarias para que la familia participe en la toma de decisiones en la escuela. Siendo esto una verdadera y efectiva preparación para una vida ciudadana activa donde la familia se involucre tempranamente en la construcción de redes

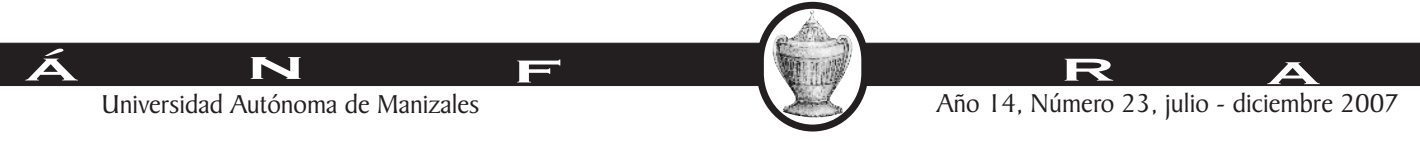


sociales, en las que no sólo les toca vivir, sino de las que son responsables.

Es justamente la nueva relación la que puede generar un nuevo "capital social de puente" en la medida que podrán potenciar sus actividades y formas de educar en beneficio de los niños y los jóvenes, pues como lo afirma Durston $(2000,2002)$ el capital social de puente:" es una extensión del capital social referida a los vínculos que dan acceso a personas e instituciones distantes, tanto horizontales como verticales. Su importancia radica en que facilita el acceso a otras formas de recursos, económicos, sociales, culturales y políticos".

\section{CONCLUSIONES.}

La familia y la escuela perdieron su identidad y su capacidad de socializar a los individuos a partir de principios estables. De ahí que los valores y las normas ya no pueden ser percibidos como valores trascendentales existentes por encima de los individuos, hoy más que nunca aparecen como producciones sociales en las cuales las nuevas formas culturales que involucran cambios de hábitos, intereses, valores desembocan en nuevas formas de interacción cambiantes, mediante las cuales los individuos constituyen sus experiencias y se construyen ellos mismos como actores y como sujetos.

La ausencia de modelos preestablecidos propone a las familias y a la escuela, redefinir el propio marco valorativo y representativo desde el cual deben acompañar el desarrollo de los niños, niñas y los jóvenes.

El rol de las instituciones socializantes por excelencia como son la escuela y la familia no es transmitir un mensaje prefigurativo sino preparar para tomar posición en los debates, saber elegir entre las múltiples opciones, construir su posicionamiento frente a la vida y saber transmitir recursos para moverse en espacios marcados por la incertidumbre.

Lo anterior solo se puede conseguir en la medida que la familia y la escuela inicien juntas un camino de puesta en marcha de un proceso de reconversión de la practica educativa, a través del conocimiento de sus niños, niñas y jóvenes con diagnósticos de sus propias realidades y no de la realidades impuestas por los medios masivos de comunicación,

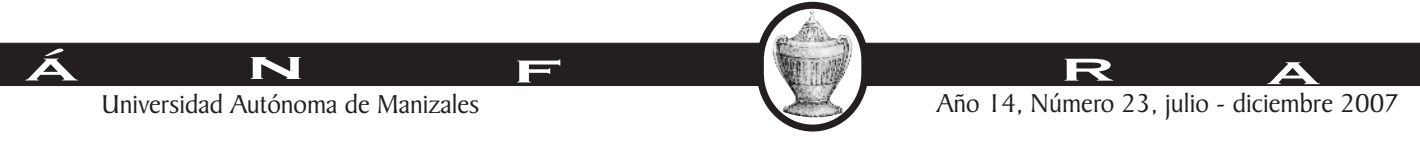


pues estos últimos son por si mismos productores de realidades y eso hace que se tomen decisiones desarticuladas y descontextuadas en relación a lo que los niños y jóvenes quieren en su proceso educativo. Esta nueva relación y el nuevo conocimiento construido por la nueva alianza determinarán nuevos niveles de capital social de puente, en la medida en que se establezcan nuevas formas de creación y recreación de conocimiento y formas de relaciones que antes, sin acción concertada era imposible de conseguir.

\section{REFERENCIAS}

ALARCÓN, D; Quezada M. y Llaña M. (1998). Revista Enfoques Educacionales Vol.1 N02 Departamento de Educación Facultad de Ciencias Sociales. Universidad de Chile.

ATRIA, R. (2001). Capital social: concepto, dimensiones y estrategias de desarrollo. Apuntes de clases, Diploma Internacional sobre Estrategias de Reducción de la Pobreza en América Latina. Universidad de Chile Banco Mundial, 2001

AGUILAR, M. (2001).Concepto de sí mismo. Familia y Escuela. Ed. Dykinson. Madrid.

ÁLVAREZ, Alejandro. (2003). ¿Hacia la sociedad educadora?. Los medios de comunicación y la sociedad educadora. ¿ Ya no es necesario la Escuela?. Historia de la práctica pedagógica. Cooperativa editorial Magisterio.

BENAVIDES, J; Gálvez, G y otros. (2000). Proposiciones para promover relaciones colaborativas. Entre familia y escuela. Documento elaborado por el Equipo Familia-Escuela del Programa de las 900 Escuelas. www.mineduc.cl.

BERNARD, H. (1983). Human Development in Western Culture. Boston: Allyn and Bacon. 4th. ed.

CEBOTAREV, N. (2003). Familia, socialización y nueva paternidad. Revista Latinoamericana de ciencias sociales, Niñez y juventud Manizales, Vol. I, No. 2.

DURSTON, J. (1999). Construyendo capital social comunitario. en Revista de la CEPAL N 69. Santiago. 
DURSTON, J. (2000). "Qué es capital social comunitario". Serie Políticas Sociales N 38 Santiago de Chile, CEPAL.

DURSTON, J; Miranda, F. (2001). "Capital Social y Políticas Públicas en Chile, Investigaciones recientes". Serie Políticas Sociales. Nº 55.

DURSTON, J. (2002). "Capital Social - Parte del problema, Parte de la Solución. Su papel en la persistencia y en la superación de la pobreza en América Latina y El Caribe". CEPAL.

DOWLING, E; OSBORNE, E. (1996)."Marco teórico: un enfoque sistémico conjunto a los problemas educativos con niños". Familia y escuela. Una aproximación conjunta y sistemática a los problemas infantiles. Compilado. Editorial Paidos. Barcelona.

FLANDRIN, J.L. (1979). Orígenes de la familia moderna. Editorial crítica. Grupo editorial Grijalbo. Barcelona.

GARCÍA, M.C. (2003). La participación de los padres como factor de calidad en programas de desarrollo humano y desarrollo social. En: Primera infancia y desarrollo. El desafío de la década. ICBF, Alcaldía Mayor de Bogotá D.C, SAVE DE CHILDREN, UNICEF, CINDE.

HABERMAS, J. (1983). La reconstrucción del materialismo histórico. Madrid. Taurus.

Instituto Nacional de Calidad y Evaluación (INCE), (1997). Madrid. Familia, escuela y medios de comunicación ante los valores: www.ince.mec.es

Instituto Nacional de la Juventud de Chile, Observatorio de Juventud. Transformaciones Culturales e Identidad Juvenil en Chile. La juventud frente a los desafíos culturales. PNUD. N.9.

KLIKSBERG, B. (1999). Capital social y cultura, claves esenciales del desarrollo. En Revista CEPAL Na 69, Santiago.

KLIKSBERG, B. (1997). ¿Cómo enfrentar los déficits sociales de América Latina?. En Cuadernos de Ciencias Sociales. FLACSO-Sede Costa Rica, No. 102. 
Ley 115 de 1994. Ley General de Educación en Colombia.

LÓPEZ N; tedesco, J. (2002). Las condiciones de educabilidad de los niños y los adolescentes en América Latina. Instituto Internacional de Planeamiento de la educación. Buenos Aires.

MAILlO, A. (1964). Acción social de la escuela. Monografías del proyecto principal para la extensión y mejoramiento de la educación primaria en la América Latina. Oficina regional de educación de la UNESCO. Santiago de Chile.100pag.

Ministerio de Planificación y Cooperación (MIDEPLAN) del Gobierno de Chile (2002). Síntesis de los principales enfoques, métodos y estrategias para la superación de la pobreza. En el marco del Seminario "Perspectivas Innovativas en Política Social. Experiencias relevantes para la superación de la pobreza: Una mirada desde lo posible",. www.mideplan.cl

NORODOWSKI, M. (1999). Después de clase. Desencantos y desafíos de la escuela actual. Argentina, Buenos Aires. Ediciones novedades educativas.

RICO, A. (1999). Formas, cambios y tendencias en la organización familiar en Colombia. Las familias contemporáneas. Nómadas. N. 11. -Rodríguez, E.(2002).Cultura juvenil y cultura escolar en la enseñanza media del Uruguay de hoy: un vinculo a construir. Ultima DÉCADA CIDPA ediciones. Viña del Mar Año 10. N. 16. pp 53-95.

SOTO, V. (1996): "Teorías críticas y currículo". Santiago: UMCE.

SAPIAINS, A; Zuleta, P. (2001). Representaciones Sociales de la escuela en jóvenes urbano populares desescolarizados. Ex-cuela y juventud popular: la escuela desde la desescolarización. Última DÉCADA, CIDPA ediciones. Viña del Mar, N015 pp. 53-72.

TEDESCO, J.C. (2003). Jóvenes, construcción de la identidad y educación. Conferencia. 